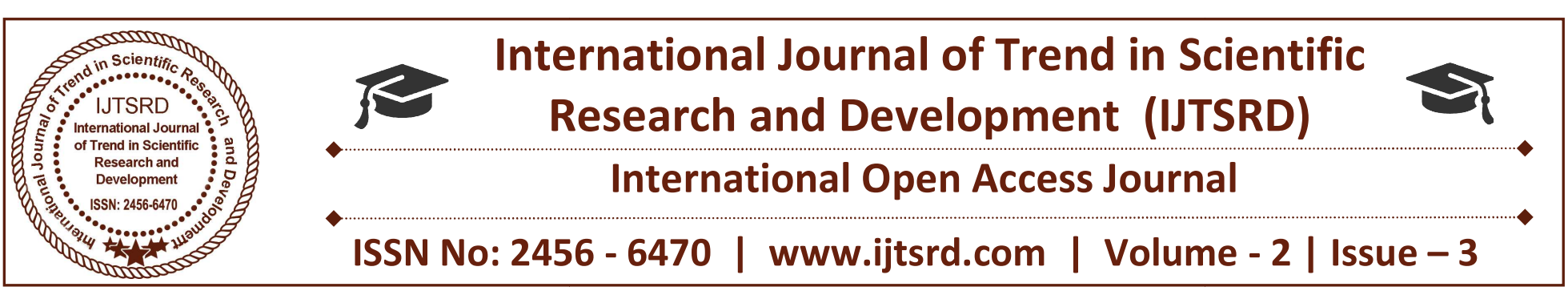

\title{
Development of 1.8 M Diameter Dish Reflector using Fiberglass Materials at Ku-Band Applications
}

\author{
Olabisi Olusegun \\ Department of Science Laboratory Technology, \\ LadokeAkintola University of Technology, Oyo State, Nigeria
}

\begin{abstract}
This paper describes the design, simulation and development of parabolic reflector using fiber glass. The antenna is $1.8 \mathrm{~m}$ in diameter, for operation at $\mathrm{Ku}-$ band $(10.95-12 \mathrm{GHz})$. An f/d ratio of 0.43 was chosen and other parameters were computed. The $\mathrm{S}$ parameters for the antenna were obtained using Design-Expert 6.0.8 Software Version and Advance Design System (ADS). The properties of the antenna such as bandwidth, beam width, gain, directivity, return loss and VSWR were obtained. The antenna offers high efficiency and high gain. The fiberglass has good surface accuracy with a light weight of 20 $\mathrm{kg}$.
\end{abstract}

Keywords: radiation pattern, fiberglass, parabolic reflector, VSWR, moulding

\subsection{INTRODUCTION}

An antenna is a metallic conductor that is cut into size and shape which radiates and receives electromagnetic waves effectively. The major function of an antenna is to couple radio waves in free space to an electrical current used by a radio receiver or transmitter. In reception, the antenna intercepts some of the power of electromagnetic waves in order to produce a tiny voltage that the radio receiver can amplify. Antennas are of different types based on their frequency of operation, application and characteristics [1].Currently, parabolic reflector is used to receive the ku-band signals. The dish provides the best compromise of high gain, which is about $37 \mathrm{~dB}$ at $12.5 \mathrm{GHz}$ for $0.6 \mathrm{~m}$ diameter, $38.5 \mathrm{~dB}$ for $0.75 \mathrm{~m}$ and $40.3 \mathrm{~dB}$ for $0.9 \mathrm{~m}$ [2].A parabolic dish antenna has a reflector which is a section of a parabolic reflector. Parabolic dish reflector antenna contains characteristics of high directivity, extremely low side lobes, pencil beam radiation pattern and high gain [3].As a result, they are widely used in the fields of point to point and satellite communication at microwave regions.

A dish antenna has a reflector, which is a section of a normal parabolic reflector. If the section does not include at the center of the reflector, then none of the radiated beam is received by Low Noise Block (LNB) the in feed antenna and support structure. For small dishes, feed blockage in an axial feed dish causes a significant loss in efficiency. In this paper, using a fiberglass material to for the parabolic reflector instead of metal is considered.

\subsection{DESIGN}

The value of $\mathrm{f} / \mathrm{d}$ employed is 0.43 for efficient performance. The higher the ratio of $\mathrm{f} / \mathrm{d}$ the shallower the dish, with higher directivity and gain [4].

$\mathrm{f} / \mathrm{d}=$ focal length to diameter ratio

$\mathrm{f}=0.77 \mathrm{~m}$

The depth of the dish, $\mathrm{D}$ is given as

$D=d^{2} / 16 f$

$\mathrm{D}=0.26 \mathrm{~m}$

The dish aperture Ap is given as

$A p=\pi(d / 2)^{2}$

Ap $=0.785 \mathrm{~m}^{2}$ 
The wavelength $(\pi)$ is

$\lambda={ }^{c} / f$

$\lambda=0.027 \mathrm{~m}$

The E-field and H-field are given by [5]

$E_{\theta}=\frac{j k e^{-j k r}}{4 \pi r}(1+\cos \theta)(f x \operatorname{Cos} \theta+f y \operatorname{Sin} \theta)$

$E \phi=\frac{-j k e^{-j k r}}{4 \pi r}(1+\cos \theta)(f x \operatorname{Sin} \theta-f y \operatorname{Cos} \theta)$

(5)

The parabolic reflector gain, $\mathrm{G}$ is given by [6]

$\mathrm{G}=\left(4 \pi \epsilon \mathrm{G}_{\mathrm{P}} \mathrm{A}_{\mathrm{P}}\right) / \lambda^{2}$

$\mathrm{G}=40.6 \mathrm{~dB}$

The reflection coefficient $\rho$ is given as

$\rho=\frac{Z_{A}-Z_{0}}{Z_{A}+Z_{0}}$

$\mathrm{Z}_{\mathrm{A}}=$ Antenna Impedance

$\mathrm{Z}_{\mathrm{o}}=$ Characteristics Impedance

$\rho=0.04961$

The voltage standing wave ratio is given as

$V S W R=\frac{1+|P|}{1-|P|}$

(8)

$\operatorname{VSWR}=130$

The return loss is given as

(7)
Return loss $=-20 \log |\rho|$

$R_{L}=-20 d B$

\subsection{MATERIALS}

Table 1: Formulation of a standard fiber glass moulding [7]

\begin{tabular}{|l|l|}
\hline Composition & Percentage Content \\
\hline Polyester resin & 30 \\
\hline Fiber mat & 18 \\
\hline Filler & 48 \\
\hline Pigment & 3 \\
\hline Grease & 0.6 \\
\hline Catalyst & 0.3 \\
\hline
\end{tabular}

\subsection{RESULTS AND DISCUSSION}

The simulation of the parameters for the antenna was done using Design Expert software (6.8.0) design System, Fig. 1 Shows the radiation pattern side lobes in polar form; Fig.2 and Fig.3 Shows the E- and HGain and Directivity, and Fig. 4 Shows the Return loss of fiberglass parabolic antenna. The antenna resonates at $10 \mathrm{GHz}$ at a return loss of $-20 \mathrm{~dB}$ with directivity and gain of $25 \mathrm{~dB}$.

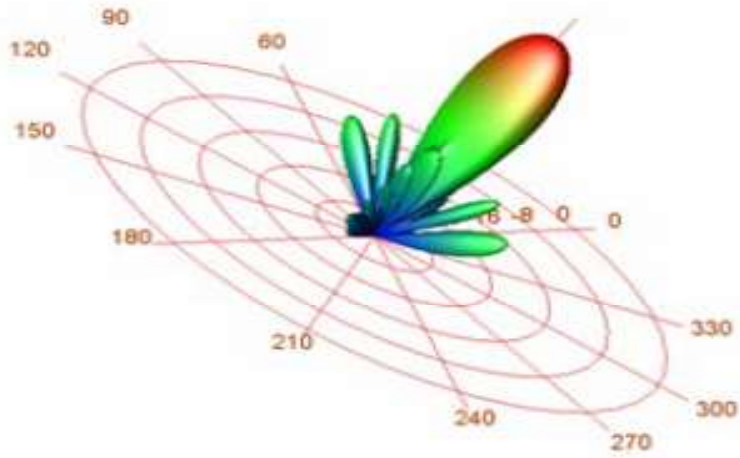

Fig. 1 Shows the3-D radiation pattern with side lobes in polar form

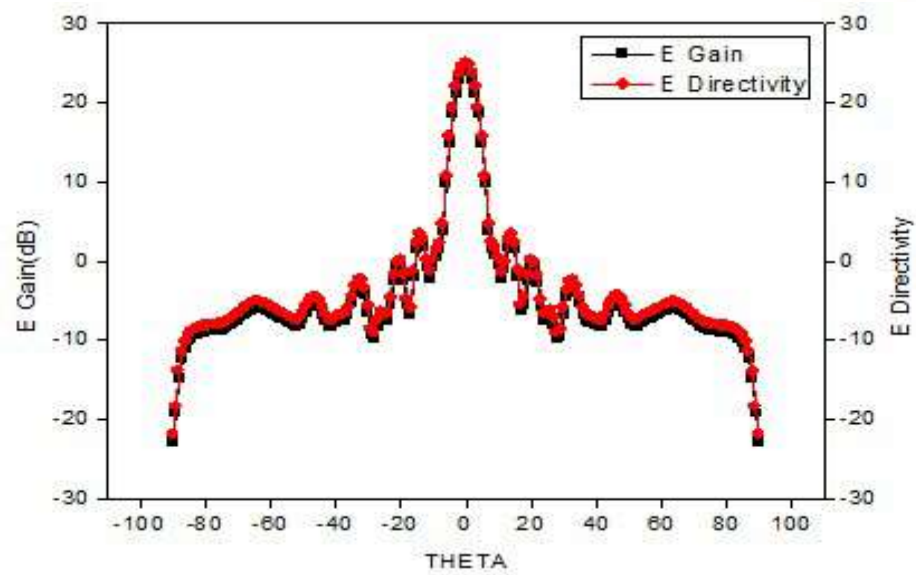

Fig. 2 Shows the E- Gain and Directivity 


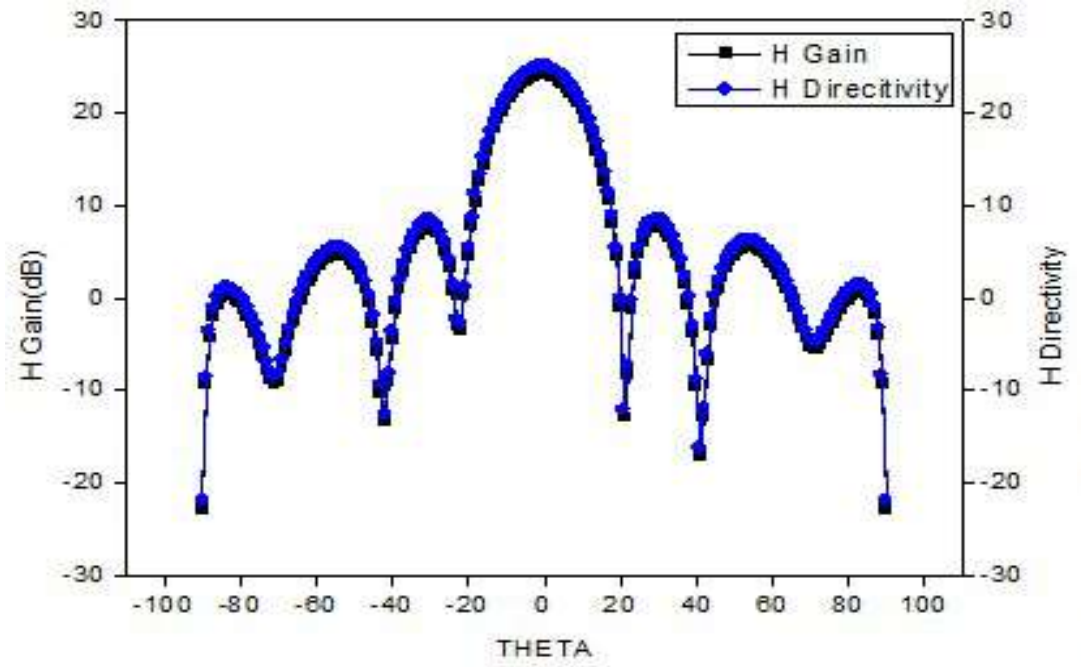

Fig 3 Shows the H-Gain and Directivity

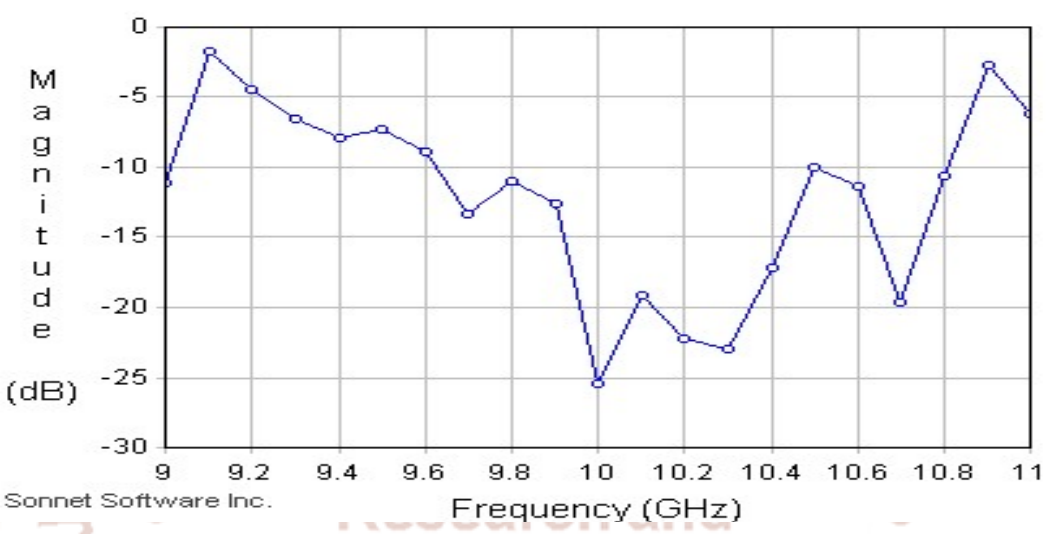

Fig 4. Shows the Return loss

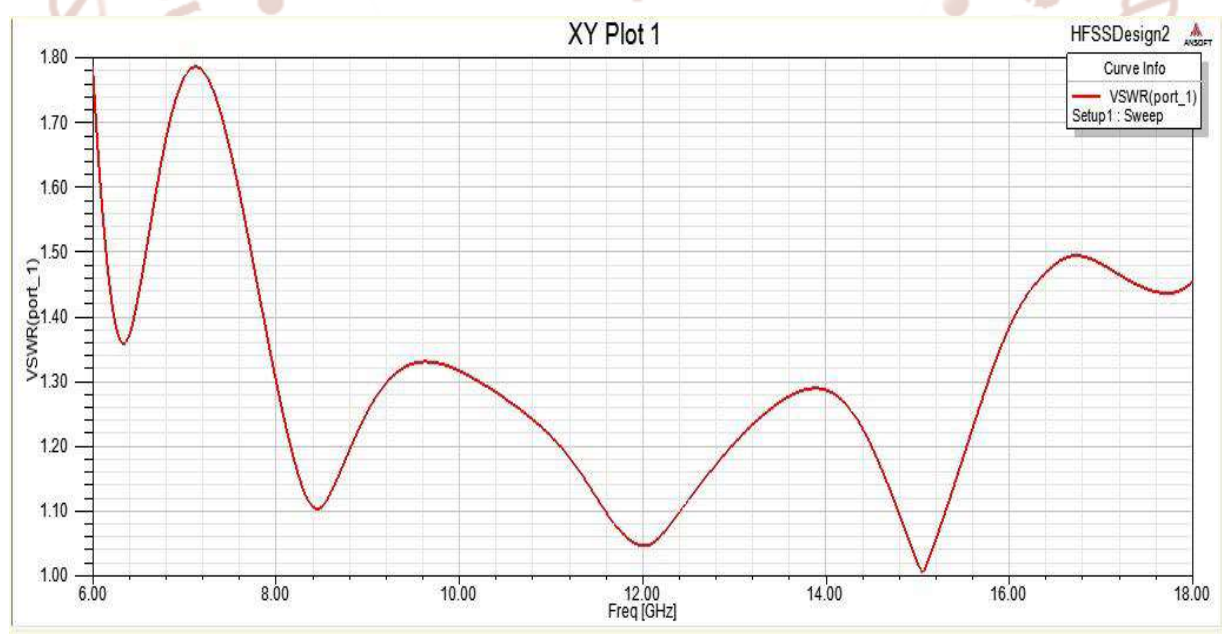

Fig 5. Shows the VSWR

\subsection{CONCLUSION}

In this paper, a fiberglass parabolic reflector antenna has been presented. The antenna has been designed to operate at $(10.95-12 \mathrm{GHz})$ in the Ku-band. The antenna has good pattern and proper. The design has been accomplished using commercially available
Design-Expert 6.0.8 Software Versionand Advance Design System (ADS) with multiple interface. The design antenna has shown good performance in terms of return loss, VWSR and radiation patterns. The percentage compositions of materials required for 
moulding of the antenna have also been presented. Good performance has been obtained for the envisaged applications.

\section{ACKNOWLEDGEMENTS}

Theauthor sincerely appreciate the contribution of the communication physics research group of LadokeAkintola university of technology Ogbomoso, Nigeria for the release of GSP-730 spectrum analyser.

\section{REFERENCES}

1. M.O Alade and O. Olabisi, "Development of microstrip patch antenna for Terrestrial indoor TV Reception" International Journal of Advanced Research in Electrical Electronics and Instrumentation Engineering, 2013, 2(6): 27272735

2. J.H.A Jadal, "Effect of rain on Ku-Band satellite system" International Journal of Electrical and Electronics Engineering, 2015, 4(2): 13-23.

3. A.H Aghvami and I. Robertson, "Power Limitation and High- Power amplifier nonlinearities in on -board satellite communication systems" Journal of Electronic Communication Engineering, 1993, 5(2): 65-70

4. N. Ranuka, I. Widad, and J.S Mandeep " Raininduced attenuation for Ku-Band Satellite Communication in the west coast of Peninsular Malaysia, Penang", Ann. Telecommunication,
2012, Institute minutes- Telecom and springerverlag2012,27 April 2012.

5. T. Sivapriya and T. Nizhanthi, "A study on the effects of Rain Attenuation for an X- Band satellite System over Malaysia", Progress in Electromagnetic Research B, 2012, 45: 37-56.

6. T.F Lai, W.N.L Mahadi and N. Soin" Circular Patch Microstrip Array Antenna for Ku-Band", World Academy of Science,Engineering and Technology,2008,48: 298-302.

7. M. Gerard and B. Michel, " satellite communication System, System, Techniques, and Technologies", Willey, Book, $5^{\text {th }}$ edition, John Willey and sons Ltd, 2009.

\section{AUTHOR BIOGRAPHY}

Olabisi Olusegun, he received his first degree in pure and applied physics (Electronic Option) in 2002 from Ladoke Akintola University of Technology, Ogbomoso, Nigeria. In 2008, he graduated with distinction M.Tech in Electronics and Communication Physics from the same institution in 2008. He obtained $\mathrm{PhD}$ in Electronics Communication Option in 2015. He is a senior lecturer in the department of laboratory technology in Lautech, Nigeria. His research interests include; design, construction and analysis of antenna and electronic devices, and radio wave propagation. 